\title{
ANOS 90 \\ uma década perdida para o sistema nacional de inovação brasileiro?
}

Arlindo Villaschi

\begin{abstract}
Resumo: O artigo argumenta que a combinação de três fatores contribuiu para o fraco desempenho do sistema brasileiro de inovação nos anos 90 , principalmente quando comparado com a de seus principais competidores no mercado globalizado: no domínio econômico, foram baixos os investimentos em áreas onde a incorporação de novos conhecimentos é essencial; no domínio tecnológico, cortes em áreas (educação, P\&D, etc.) essenciais para inovações em tempos de economia do aprendizado; no domínio institucional, a adoção da não política industrial/tecnológica como política de desenvolvimento.

Palavras-chave: Economia do aprendizado. Sistema de inovação. Política tecnológica.

Abstract: The paper argues that the combination of three factors contributed for a poor performance of the Brazilian national system of innovation in the 1990s, specially when compared with it competitors in the global economy: in its economic domain there was not enough productive investment in areas where new knowledge is essential; in the technological domain, curb of expenses in areas (education, R\&D, etc. ) which are crucial to innovation at times of the learning economy; and in the institutional domain, the adoption of industrial/technological policies as its policy of economic development.

Key words: Learning economy. Systems of innovation. Technological policy.
\end{abstract}

$\mathrm{E}$

ste trabalho trata das mudanças estruturais que ocorreram na formação socioeconômica brasileira na década de 90 e de seu impacto sobre os elementos mais importantes do sistema nacional de inovação brasileiro - SNIB. Seguindo uma tradição que começou com Freeman (1987) e Andersen e Lundvall (1988), destacam-se neste estudo as interações entre os atores econômicos, sociais e políticos que fortalecem ou restringem suas capacidades de aprendizado e pesquisa e, como resultado, aumentam ou inibem o desenvolvimento, a divulgação e o uso de inovações em uma determinada nação.

Apesar da nova estrutura dessas interações em uma era de relações cada vez mais intensas em escala mundial, dáse ênfase à dimensão nacional a fim de se captar a referência espaço-institucional das trocas focadas nos proces- sos de aprendizado que levam à inovação e aumentam ou inibem a competitividade das empresas e as capacitações sociais. O caso brasileiro é peculiar no sentido de que a maioria das mudanças em sua estrutura institucional e econômica (privatização, liberalização, mudança na participação acionária de importantes empresas que alteraram sua condição de local para estrangeira, etc.) na década de 90 não levou em conta as transformações radicais que estavam ocorrendo na base tecnológica do desenvolvimento mundial - ou seja, as mudanças associadas ao paradigma técnico-econômico - PTE das tecnologias da informação e das comunicações - TICs (FREEMAN; PEREZ, 1988).

Assim, são revistos alguns dos elementos dinâmicos do SNIB identificados nos anos 80 por Villaschi (1992). Na época, o papel desempenhado pelas empresas estatais e 
pelos laboratórios de pesquisa públicos em áreas que estavam no cerne do PTE da TIC e a maneira como a tripla aliança entre empresas locais, estrangeiras e estatais vinha funcionando poderiam ser uma indicação positiva de possibilidades para o SNIB aproveitar algumas 'janelas de oportunidades' que estavam sendo abertas pelo emergente PTE. Além disso, essas oportunidades pareciam ser apoiadas pelas mudanças institucionais promovidas pelo incremento da participação social subjacente à Constituição de 1988.

Após aproximadamente uma década, o presente trabalho mostra que algumas dessas indicações falharam e não se cumpriram as expectativas levantadas pelo estudo anterior. Muito embora a economia tenha superado o problema histórico da instabilidade de preços, o desempenho do investimento foi fraco na década de 90, e a liberalização do comércio e o fluxo de capitais não trouxeram investimentos externos produtivos para áreas em que novos conhecimentos são essenciais. No domínio tecnológico, o compromisso político com o déficit público tem implicado corte nos gastos em áreas cruciais para a inovação em tempos de aprendizado econômico educação, pesquisa e desenvolvimento (P\&D), etc. Ademais, no domínio institucional, uma forte crença nas forças do mercado por parte das autoridades governamentais levou o país à adoção de "não-políticas" industriais e tecnológicas como sua política de desenvolvimento econômico.

Este artigo, portanto, reforça o que é ressaltado pela literatura neo-schumpeteriana, ou seja, que os rumos emergentes de um PTE são, raramente, dirigidos 'naturalmente' pelas forças do mercado. Fatores tecnológicos, econômicos e sociopolíticos são muito importantes na formação das trajetórias e na determinação do modo como a nova base tecnológica para o desenvolvimento mundial evolui nos diferentes países. Essas trajetórias são formadas por um processo de seleção que ocorre pela interação de forças econômicas, políticas e sociais e de recursos científicos, tecnológicos, inovadores e industriais locais.

Como os atores econômicos, sociais e políticos que constituem um sistema nacional de inovação - SNI não respondem a uma lógica única e as diversas lógicas a que eles respondem não são necessariamente convergentes, os elementos do SNIB destacados serão divididos em três domínios auto-regulados (tecnológico, econômico e institucional), que operam de acordo com as hipóteses estabelecidas por Dosi (1984) e posteriormente utiliza- das por Villaschi (1992) para examinar suas principais características nos anos 80.

Portanto, o SNIB é visto aqui de uma maneira que responde às características básicas identificadas por Edquist (2001). Primeiro, ele consiste de alguns tipos de componentes e das relações existentes entre eles. Segundo, o motivo da escolha de uma série de componentes (tecnológicos, econômicos e institucionais) e relações (em especial as que não são mediadas pelo mercado) são os indícios de que eles formam um todo. Terceiro, esses componentes e suas relações são escolhidos com vistas a facilitar a caracterização do sistema em relação ao resto do mundo - isto é, deve ser possível identificar as fronteiras do sistema. Ou seja, pelo menos um ator do processo de aprendizado, pesquisa, inovação e produção está dentro das fronteiras geopolíticas do país.

A próxima seção apresenta a estrutura analítica utilizada na avaliação do SNIB, baseada:

- nas contribuições de Freeman (1988) e Lundvall (1988) relativas à abordagem do SNI e nas críticas a ela feitas por Edquist (2001);

- nos trabalhos de Freeman e Perez (1988), Freeman e Louçã (2001), Castells (2000) e Tuomi (2001) sobre o paradigma técnico-econômico corrente;

- nas formulações de Johnson e Lundvall (2001), Nonaka e Takeuchi (1995) e Kuusi (1999) relativas a conhecimento e aprendizado;

- nas análises das instituições e capacidades sociais elaboradas por Hämäläinen (1999) e Perez (1997).

A seção seguinte trata dos elementos dos campos tecnológico, econômico e institucional do SNIB na década de 90. Dá-se especial atenção: à redução de recursos disponíveis para o ensino e a pesquisa em universidades públicas do país; à debilidade da política econômica nos aspectos da estabilidade e flexibilidade necessárias para que o país desempenhasse um papel relevante no PTE da TIC e à estratégia defensiva com relação à inovação usada por empresas, mesmo em se tratando daquelas localizadas nas regiões mais desenvolvidas do país.

Diante das indicações de que os anos 90 foram uma década em que o SNIB funcionou sob pesadas restrições, a última seção lida com questões prioritárias na agenda dos países que desejam desempenhar um papel mais ativo no fluxo mundial de bens e serviços intensivos em conhecimento, e que também devem tornar-se parte do debate público e da elaboração de políticas no Brasil. 


\section{ESTRUTURA ANALÍTICA}

\section{Abordagem de Sistema de Inovação}

A tradição iniciada com Freeman (1987) e Andersen e Lundvall (1988) ressalta as diferenças no ritmo em que os países exploram as possibilidades oferecidas pelo hiato tecnológico que se abre especialmente em tempos de mudança do paradigma técnico-econômico ou das trajetórias tecnológicas (FREEMAN; PEREZ, 1988). Essas diferenças são vistas como dependentes da capacidade de cada país de mobilizar recursos políticos e financeiros para transformar as estruturas tecnológicas, institucionais e econômicas que englobam seu sistema nacional de inovação - SNI. ${ }^{1}$

Como é ressaltado na literatura neo-schumpeteriana, as trajetórias emergentes de um PTE são raramente movidas 'naturalmente' por fatores endógenos científicos e tecnológicos. Os fatores econômicos e sociopolíticos são muito importantes na formação das trajetórias e na determinação da maneira como uma nova base tecnológica para o desenvolvimento mundial se desdobra em diferentes países. Um processo de seleção ocorre, então, mediante a interação de forças econômicas, políticas e sociais e de recursos científicos, tecnológicos, inovadores e industriais locais.

Para captar as principais características da interação que ocorre em qualquer país, o SNI deve ser visto de dois ângulos interconectados e, ao mesmo tempo, opostos. O primeiro é o do conteúdo 'desequilibrador' das forças que interagem dentro dele. Isso acontece porque as mudanças e transformações são, por natureza, forças não-equilibradoras. O segundo ângulo sob o qual o SNI deve ser visto é o das forças que mantêm relativamente ordenadas as configurações do sistema e permitem uma ampla coerência entre suas condições de reprodução material.

Como os atores econômicos, sociais e políticos que compreendem um SNI não respondem a uma lógica única e as diferentes lógicas a que cada um responde não são necessariamente convergentes, os elementos do SNIB aqui destacados serão divididos em três domínios autoregulados (tecnológico, econômico e institucional), que operam de acordo com as seguintes hipóteses (DOSI, 1984):

- independentemente das poderosas interações entre eles, cada um dos três domínios tem uma dinâmica e um conteúdo próprios. As especificidades da dinâmica e do con- teúdo de cada domínio moldam e restringem seu impacto individual e as interações entre eles, de maneira que suas retroalimentações funcionais podem tornar possíveis 'círculos virtuosos' quanto 'desajustes';

- os 'mundos possíveis' são limitados pelo número de configurações em que os três domínios podem operar de maneira relativamente 'bem regulada' e harmoniosa;

- os desequilíbrios ou 'desajustes' entre os três domínios não levam necessariamente a mudanças em outras configurações mais equilibradas ou 'mais harmoniosas';

- a adaptabilidade do sistema tecnológico para um dado ambiente econômico e social é confinada e limitada. Inversamente, um conjunto relativamente limitado de condições macroeconômicas e relações sociais é 'dado' em cada estágio do 'domínio tecnológico'.

\section{O Paradigma Técnico-Econômico - PTE das TICs como Base para o Desenvolvimento Mundial}

Muito embora se reconheça a importância dos outros três 'níveis' de inovação propostos por Freeman e Perez (1988) - mudanças incrementais e radicais do sistema de tecnologia -, a principal preocupação aqui será com as mudanças tecnológicas revolucionárias. Dois aspectos dessas transformações merecem ser destacados: primeiro, a sua difundida aplicação e a drástica redução nos custos de muitos produtos e serviços; e, segundo, a importância de se prestar atenção na aceitabilidade social e política das revoluções tecnológicas. Isso pode levar mais tempo do que aquele necessário para a percepção das vantagens técnicas da inovação e da sua economicidade. Por isso, em muitos casos, essa receptividade deve ser expressa em mudanças legislativas, educacionais e de regulação de processos econômicos, sociais e políticos.

Assim, o conceito de PTE de Freeman e Perez (1988) é uma boa aproximação da elaboração de Kuhn, porque eles relacionam o paradigma tecnológico não apenas a um ramo setorial particular, mas às tendências amplas da economia. Além disso, juntam a inadequação das instituições ao pleno desenvolvimento de uma revolução tecnológica e ao estado de crise que, mais cedo ou mais tarde, emerge da diminuição de seu caráter revolucionário. Ou seja, eles dão algum conteúdo real à noção de 'sucessivas revoluções industriais', interpretando as ondas de Kondratiev como graus crescentes de ajustes entre o sistema técnico-econômico e a estrutura socioinstitucional em expansão, seguidos de 
graus crescentes de desajustes entre esses subsistemas à beira do colapso.

Ademais, ao romper com os diferentes graus de determinismo econômico monocausal, a abordagem do PTE pode ser vista como um importante movimento em direção a uma teoria unificada de crescimento, crise e mudança. Essa abordagem heterodoxa parece mais adequada que o círculo vicioso das atuais ciências sociais, em que, de um lado, os sociólogos e cientistas políticos tentam explicar as fracas motivações sociais, a apatia e a crise política em termos de tendências econômicas e, de outro, os economistas tentam explicar as tendências da crise econômica como o resultado da politização da economia em relação a motivações e incentivos.
Esse tratamento heterodoxo torna-se ainda mais importante quando se deseja lidar com a mudança contínua no PTE. Mesmo que seja possível remontar a suas raízes científicas e tecnológicas no século XVII, ${ }^{2}$ o PTE das tecnologias da informação e das comunicações somente se tornou parte da agenda econômica depois de 1970. Além disso, suas implicações institucionais somente chegaram ao debate público na década de 90 .

Independentemente de quando cada uma dessas três dimensões do PTE das TICs aflorou no debate acadêmico ou público, ${ }^{3}$ o que importa é ter em mente que se deve evitar a armadilha do determinismo do fator único, qualquer que seja ele - cultural, econômico, político, científico ou tecnológico (FREEMAN; LOUÇÃ, 2001). ${ }^{4}$

QUADRO 1

Mudanças no Paradigma Técnico-Econômico: da Energia Barata ao Chip

\begin{tabular}{|c|c|}
\hline Fordista (antigo) & TICs (novo) \\
\hline \multicolumn{2}{|l|}{ Características tecnológicas } \\
\hline Funcionalidade e "melhores" produtos & $\begin{array}{l}\text { Conhecimento e comunicação } \\
\text { vinculados com a mente humana }\end{array}$ \\
\hline Conectividade local-a-local & Conectividade pessoa-a-pessoa \\
\hline $\begin{array}{l}\text { As pessoas vistas como usuários, consumidores, } \\
\text { trabalhadores }\end{array}$ & $\begin{array}{l}\text { Sustentabilidade pessoal, física e } \\
\text { psicológica }\end{array}$ \\
\hline \multicolumn{2}{|l|}{ Características econômicas } \\
\hline Intensivo em energia & Intensivo em informações \\
\hline Projetos e engenharia em escritórios de desenho & Projetos auxiliados por computador \\
\hline Projeto e produção seqüencial & Engenharia simultânea \\
\hline Automação & Sistematização \\
\hline Empresa única & Redes \\
\hline Produto com serviço & Serviço com produto \\
\hline Centralização & Informação distribuída \\
\hline Habilidades especializadas & Múltiplas habilidades \\
\hline \multicolumn{2}{|l|}{ Características institucionais } \\
\hline Controle e, às vezes, propriedade do governo & $\begin{array}{l}\text { Informações, coordenação e } \\
\text { regulamentação do governo }\end{array}$ \\
\hline Planejamento & Visão \\
\hline Estado do bem-estar e Estado bélico & $\begin{array}{l}\text { Regulamentação da infra-estrutura } \\
\text { estratégica das TICs }\end{array}$ \\
\hline $\begin{array}{l}\text { Pax Americana - predomínio econômico e militar } \\
\text { dos EUA }\end{array}$ & $\begin{array}{l}\text { Multipolaridade - blocos } \\
\text { regionais }\end{array}$ \\
\hline Dominação americana dos regimes financeiro & Problemas de desenvolvimento \\
\hline \multirow[t]{4}{*}{ e comercial internacionais } & de instituições internacionais \\
\hline & (FMI, Banco Mundial, etc.) \\
\hline & apropriadas capazes de regular as \\
\hline & finanças globais \\
\hline
\end{tabular}

Fonte: Adaptado de Freeman e Perez (1988); Freeman e Louçã (2001) e Tuomi (2001). 
Por esse motivo, aqui se dispensa ênfase especial a duas características da era emergente que são reconhecidas como relevantes por todos os que estão preocupados com suas oportunidades e limitações: conhecimento e instituições. Ressalte-se, portanto, que a grande diferença entre as ondas/revoluções/sociedades/gerações anteriores e a atual reside no fato de que hoje existem formas novas e mais rápidas e conteúdos diferentes (sociais, políticos, econômicos, etc.) para a coleta, o tratamento, a transmissão e o recebimento de todos os tipos de informações de qualquer lugar e para todos os lugares.

\section{Informação, Conhecimento e Aprendizado}

A economia moderna está mais do que nunca consciente da importância do conhecimento e do aprendizado. No campo dos estudos da inovação e das mudanças tecnológicas, Nelson e Winter (1982), por exemplo, têm feito amplo uso da distinção entre conhecimento tácito e codificado; Arrow (1962), Rosenberg (1976) e Lundvall (1985) levantam questões específicas relativas ao aprendizado e à inovação. A maior diferença entre essas contribuições é que, enquanto os dois primeiros estão mais interessados no aprendizado dentro da empresa (por meio do fazer e do usar, respectivamente), o aprendizado por interação de Lundvall leva à vanguarda da discussão capacitações inovativas que emergem quando usuários e produtores de inovações buscam juntos novos produtos ou processos.

Todavia, o entendimento acerca de conhecimento e aprendizado permanece ainda estreito, apesar das novas percepções que surgem de programas de pesquisas históricas e empíricas sobre economia institucional, economia evolucionária, pesquisa socioeconômica e economia da inovação. ${ }^{5}$ Deve-se creditar a esses programas o domínio maior que hoje temos sobre como a inovação acontece em diferentes partes da economia. Mas, quando se vai ao outro aspecto da produção de conhecimento, isto é, ao fortalecimento da competência, do aprendizado e da intermediação de conhecimento, somente agora a pesquisa está começando a levantar questões fundamentais sobre quem aprende o quê e como o aprendizado ocorre no contexto do desenvolvimento econômico (JOHNSON; LUNDVALL, 2001).

Para facilitar o entendimento dessas questões, Johnson e Lundvall (2001) as dividem em quatro categorias. O conhecimento individual consiste de know-what (fatos), know-why (princípios), know-how (habilidades) e knowwho. Este último refere-se a informações sobre quem sabe o quê e quem sabe o que fazer e à capacidade para coope- rar e comunicar-se com tipos diferentes de pessoas e especialistas. $^{6}$

Os estudiosos destacam, adicionalmente, que é mínimo o conhecimento perfeitamente público. Mesmo informações do tipo know-what podem não estar disponíveis para os que não estão conectados às comunicações ou redes sociais certas. ${ }^{7}$ Se os conhecimentos científicos ou de outros tipos complexos se tornassem perfeitamente acessíveis, ainda assim, para acessá-los, o usuário precisaria investir no fortalecimento de capacidades de absorção. Assim:

- apesar de a tecnologia da informação ter ampliado enormemente a disponibilidade de informações para os agentes individuais, o know-what cada vez mais depende da escolha do que é relevante. Mesmo com os mais recentes avanços nessa área, o acesso a esse tipo de conhecimento está ainda longe de ser perfeito, e o meio mais eficaz de obter os fatos pertinentes pode ser por meio do know-who - isto é, o contato com um excelente especialista na área para conseguir orientação sobre onde procurar informações específicas;

- o trabalho científico visa produzir um modelo teórico do tipo know-why, e parte desse trabalho é tornado de domínio público. Isso, porém, não significa acesso público, uma vez que, com freqüência, são necessários substanciais investimentos em aprendizado para que as informações disponíveis na Internet ou em outros meios façam algum sentido. Novamente, o know-who, direcionado para o mundo acadêmico, pode ajudar o diletante a obter uma "tradução" para algo de mais fácil compreensão. ${ }^{8}$ Esta é uma das fortes motivações para a presença de empresas em ambientes acadêmicos e, às vezes, até mesmo de seu engajamento em pesquisa básica. Algumas grandes firmas contribuem para a pesquisa básica e tendem a assumir funções de universidades técnicas. No entanto, essa estreita conexão entre a ciência e a exploração de novas idéias pelas empresas, em campos como a biotecnologia, pode comprometer o intercâmbio aberto que deve caracterizar a produção do conhecimento acadêmico; ${ }^{9}$

- em campos com intensa concorrência tecnológica, as soluções técnicas, com freqüência, passam à frente do know-why acadêmico. Esse é o caso quando a tecnologia pode resolver problemas de exercício de funções sem um entendimento científico claro do porquê. Aqui, conhecimento é mais know-how do que know-why.

Depois de tratar essas diferentes formas e conteúdos de conhecimento e suas fronteiras públicas/privadas in- 
definidas, Johnson e Lundvall (2001) abordam outra questão fundamental, especialmente no que tange a produção, circulação e distribuição de conhecimento - isto é, como seus diferentes aspectos podem ser mediados. A esse respeito, eles acrescentam:

- como o conhecimento tácito na forma de know-how ou competência não pode ser separado da pessoa ou organização que o contém, a mediação pode tomar a forma de compra dos serviços prestados pela pessoa ou empresa em detrimento da aquisição da competência. A importância desse tipo de mediação (e dos problemas envolvidos) pode ser observada na crescente relevância que os serviços empresariais intensivos em conhecimento (mencionados na literatura internacional como kibs) vêm adquirindo;

- o conhecimento tácito também pode ser mediado pelo aprendizado interativo entre quem dele precisa e seu portador. Essa pode ser uma escolha consciente - por exemplo, quando um aprendiz entra em contato com um mestre - ou pode ser um subproduto da cooperação entre pessoas e organizações para resolver problemas compartilhados.

A mediação do conhecimento não é necessariamente mais fácil quando seu conteúdo pode ser explicitado e separado de seu portador. De um lado, a determinação do valor das informações para o usuário antes da transação não é sempre uma tarefa fácil; por motivos óbvios, o usuário deseja saber algo com antecedência sobre o conhecimento e o vendedor não deseja dar informações gratuitamente. Por outro lado, é difícil tanto para o vendedor restringir o uso das informações depois que elas foram vendidas como para o comprador impedir sua posterior distribuição pelo vendedor.

Em todo caso, a importância dos gastos em P\&D tem aumentado como um meio de facilitação da mediação do conhecimento. De um lado, isso acontece porque até mesmo para a engenharia reversa se requer um mínimo de competência científica, cuja aquisição exige investimento em P\&D. De outro, como o ritmo da mudança e a complexidade do conhecimento têm crescido de maneira muito rápida, nenhuma organização sozinha pode dominar todos os elementos da base de conhecimento.

É importante observar que, mesmo quando a cognição é incorporada a produtos, pode ser necessário algum tipo de mediação para a transferência de conhecimento tácito, a fim de que ele possa ser pleno ou adequadamente usado. Esse é o motivo pelo qual os fornecedores de equipamentos para processos complexos podem oferecer treinamento ao cliente. ${ }^{10}$
Em todos os casos apresentados por Johnson e Lundvall (2001), fica bastante claro que, em tempos de mudança do PTE, toda tentativa de corte entre conhecimento tácito e codificado (ou codificável) é infrutífera. Por isso, torna-se cada vez mais importante compreender como essas duas formas de conhecimento podem estabelecer círculos virtuosos de complementaridades.

O modelo SECI (socialização-externalização-combinação-internalização), proposto por Nonaka e Takeuchi (1995), baseia-se na idéia de que o conhecimento é criado em um processo contínuo no qual a socialização do saber tácito e não-articulado o transforma em algo que pode ser transferido ou codificado. A combinação de diferentes cognições externalizadas aumenta o conhecimento tácito, que é internalizado nos indivíduos ou nas organizações participantes. Um círculo virtuoso é estabelecido quando o novo conhecimento tácito é socializado.

Como, em muitos casos, os círculos virtuosos não ocorrem como resultado de ambientes formais, mas provêm de redes informais, deve-se dar mais atenção às comunidades de aprendizado, cujo conceito envolve a maneira como atores e instituições básicas interagem na implementação de diferentes tipos de redes. As funções que definem uma comunidade de aprendizado são a gestão de seu conhecimento comum ou as atividades de logística do conhecimento que resultam na adoção ou na produção de inovações (KUUSI, 1999).

A análise desse modelo é um forte argumento para o alerta de Johnson e Lundvall (2001) sobre a necessidade de um melhor entendimento das conexões entre as diferentes formas de conhecimento, seu conteúdo público/privado e as diferentes formas de sua mediação. Também serve para o fortalecimento das possíveis implicações do contexto em que se dá a geração do conhecimento tácito. Em outras palavras, é preciso

pensar mais e com maior cuidado sobre como o conhecimento tácito e o contexto são produzidos para podermos dizer algo inteligente sobre as condições em que o conhecimento tácito possa ser o mais prontamente possível compartilhado - ou seja, quando a 'proximidade' é importante: que tipos e por quê (GERTLER, 2001, p. 17, tradução nossa).

\section{Instituições e Capacidades Sociais}

Regidas tanto por restrições informais (tabus, sanções, costumes, tradições e códigos de conduta) quanto por re- 
gras formais (constituições, leis, direitos de propriedade), as instituições, de maneira geral, "são restrições criadas pelo homem que estruturam as interações políticas, econômicas e sociais" (NORTH, 1991, p. 97). Elas têm, como característica fundamental, seus dispositivos de informação elaborados para diminuir as incertezas. Ao diminuir o volume das informações necessárias para a ação individual e coletiva, as instituições tornam a sociedade possível e constituem sua pedra fundamental.

Do ponto de vista econômico, a tradição institucionalista tem ressaltado as dimensões de tempo e local que caracterizam as regularidades do comportamento social. O comportamento econômico foi instituído, então, não por força de características humanas universais, mas por um processo cultural. Em um mundo caracterizado por atividades inovadoras (centradas em diferentes formas e conteúdos de conhecimento adquiridos de fontes e por meios de aprendizado diversos), a incerteza é um aspecto importante da vida econômica e a existência de ambientes institucionais em diferentes níveis (de uma empresa específica, de um grupo de empresas ou de um país) tornase um dos componentes centrais de um sistema de inovação.

Com essas configurações, não surpreende que em todas as abordagens mencionadas anteriormente as instituições apareçam como um elemento-chave a ser considerado. Como Freeman e Perez (1988) ressaltaram, em tempos de mudança dos PTEs, a antiga estrutura institucional sempre enfrenta novos desafios. Os recursos, as tecnologias, os arranjos organizacionais e as estruturas de mercado essenciais do novo paradigma não podem alcançar seu pleno desenvolvimento dentro da antiga estrutura institucional.

Não houvesse outra razão, o antigo ambiente institucional foi desenhado (formal ou informalmente) para combinar as necessidades e preferências sociais, econômicas e tecnológicas de seu tempo. Da mesma forma, à medida que surgem novas demandas, um novo ambiente institucional deve se instalar para evitar a perpetuação do desajuste entre os diferentes domínios descritos acima.

Esse desacordo pode ser visto sob a perspectiva da maneira como os agentes (indivíduos, grupos, organizações) percebem as mudanças que estão ocorrendo. Segundo Hämäläinen (1999):

- alguns desenvolvem uma atitude que reflete melhor as novas realidades técnico-econômicas do mundo, mas estão insatisfeitos com a lentidão do ajuste das normas sociais, das instituições formais e do comportamento coletivo;
- outros estão satisfeitos com seu antigo paradigma mental, mas não com a maneira como a economia e as tecnologias estão mudando o mundo ao seu redor;

- outros, ainda, sentem as perdas da rápida mudança estrutural ocasionadas pela mudança de PTE, mas não conseguem compreender o que aconteceu de errado com a sociedade;

- também existem os que percebem que as mudanças são inevitáveis, mas, devido a interesses adquiridos no antigo paradigma (normalmente, ligados a capital humano e patrimônio físico), expressam seus protestos contra as possíveis mudanças.

Devido a tais percepções e comportamentos distintos, Perez (2002) observa que:

- a longa fase de transição entre os antigos e novos paradigmas socioinstitucionais tende a ser um período turbulento de crescimento das tensões sociais, intensificação do fundamentalismo moral e religioso, proliferação de novos clãs e movimentos extremistas, surgimento de lideranças fortes com ideologias simples e, até mesmo, de guerras e revoluções; ${ }^{11}$

- o ajuste da estrutura jurídica e reguladora da socieda$\mathrm{de}^{12}$ pode ser um processo muito lento devido à resistência de numerosos grupos de interesses especiais e à natureza complexa do processo político;

- o processo de ajuste institucional influencia o comportamento coletivo. As organizações do setor público e os antigos grupos de interesses especiais tendem a ser os últimos redutos do antigo arranjo institucional, pois não enfrentam concorrência direta e têm um forte interesse na manutenção do antigo regime.

Por ora, deve ficar claro que um sistema de inovação não pode depender somente das relações econômicas que podem ser mediadas pelo mercado ou cuja governança pode estar a cargo de hierarquias. No nível das diferentes redes sociais e econômicas, deve-se tentar quantificar essas relações por meio da decomposição do capital social em três fatores: interação social, confiança e qualidade da informação (ALI-YRKKÖ, 2001).

Segundo Coleman (2000), os atributos/capacidades sociais podem ser compreendidos como relações institucionais entre pessoas. Putman (1993) relaciona-os com as redes sociais, as normas da sociedade e a confiança. E, usandose a contribuição de Fukyama (1995), pode-se argumentar que os atributos/capacidades sociais incluem a capacidade das pessoas de trabalhar entre si para o bem comum. 
Qualquer que seja o nível em que se deseje entender o bem comum, essas capacidades sociais são de fundamental importância para que um SNI possa lidar adequadamente com os desafios científicos, tecnológicos, econômicos e institucionais e aproveitar plenamente as vantagens das janelas de oportunidades que emergem em tempos de mudança do PTE (PEREZ; SOETE, 1988). Essa posição ganha ainda mais força quando se considera que as sociedades diferem no tocante ao capital social acumulado, e que este tem um impacto sobre sua capacidade de produção de capital intelectual e de engajamento em atividades de inovação (SCHIENSTOCK; HÄMÄLÄINEN, 2001).

\section{Características do SNIB na Década de 90}

Diante das características do paradigma técnico-econômico - PTE corrente indicadas na seção anterior e da formação socioeconômica brasileira, duas dificuldades surgem com respeito à análise do SNIB. A primeira relaciona-se com a imprecisão das fronteiras existentes entre os domínios tecnológico, econômico e institucional em tempos de mudança nos paradigmas.

A importância aqui atribuída às interações inovadoras que ocorrem entre os diferentes agentes dificulta a tarefa de encaixar cada uma delas, de forma coerente, em um desses três domínios. Por esse motivo, é inevitável um certo grau de arbitrariedade na decisão sobre o domínio no qual considerar os elementos dos processos de pesquisa e aprendizado que ocorrem no sistema.

A segunda dificuldade de análise do SNIB diz respeito aos elementos a serem considerados. Como a abordagem do aprendizado empregada tem estreita relação com uma perspectiva evolucionária sob a qual a mudança tecnológica corresponde a uma seqüência de eventos em aberto, uma característica importante dos elementos é sua contribuição à diversidade e complexidade do sistema.

Ademais, o entendimento mais amplo da inovação no âmbito do conceito do PTE e da abordagem do SNI implica que se deva dar atenção não só aos fatores orientados para o setor econômico, como para a diversidade de produtos, os padrões de produção e do comércio, mas também à diversidade institucional que pode afetar as capacidades de pesquisa e aprendizado do SNI.

Dito isso, a escolha dos elementos a serem usados na caracterização do SNIB na década de 90 recairá sobre aqueles que são vistos como indicadores de uma resposta positiva às características do PTE corrente ou de uma restrição ao SNIB no desempenho de um papel mais ativo para a melhor inserção do país nas formas e nos conteúdos novos da economia mundial.

\section{Domínio Econômico}

O impacto das mudanças na política econômica, ocorridas no Brasil na década de 90, é ainda uma questão sujeita a longas discussões. As políticas macroeconômicas para estabilizar os preços e promover reformas estruturais, seguindo as prescrições do Consenso de Washington, supostamente criariam um círculo virtuoso de ganhos em competitividade após a fase de reestruturação por meio da liberalização do comércio, desregulamentação e privatização de empresas estatais, porém, isso não pode ser dado como certo para todas as atividades econômicas do país.

Como Coutinho (2003) mostra:

- o Plano Real para a estabilização econômica do Brasil tinha taxas de juros muito altas, o que resultou em sobrevalorização da taxa de câmbio logo em seu início;

- a estabilização baseou-se em uma taxa de câmbio substancialmente sobrevalorizada, com preços altos e não facilmente reversíveis - levando a um aumento estrutural nas importações e uma desaceleração no crescimento das exportações;

- as indústrias locais aderiram progressivamente às máquinas e aos equipamentos importados, tornados irresistivelmente baratos devido à sobrevalorização da taxa de câmbio em relação aos insumos fabricados internamente;

- a parcela de importações na composição do suprimento do país aumentou e, em muitos casos, aniquilou a produção interna, levando à contração de uma porção significativa da indústria local;

- a persistente vulnerabilidade financeira das empresas de capital brasileiro foi o preço pago por custos de capital muito elevados;

- fraco desempenho competitivo, com destacada fragilidade do comércio, em todos os setores de alto valor agregado e alto conteúdo tecnológico. Somente os setores de commodities se mantiveram competitivos no plano internacional, com produção em grande escala e baixo valor agregado, principalmente aqueles que utilizam matéria-prima e insumos agrícolas e/ou são intensivos em energia;

- freqüentes perdas da propriedade nacional em muitos setores, ${ }^{13}$ debilidade e tamanho reduzido dos grupos em- 
presariais brasileiros restantes, tornando quase impossível sua participação como atores no plano mundial;

- presença crescente de investidores estrangeiros em todos os setores dinâmicos com atividades de alto valor agregado. ${ }^{14}$ É digno de nota que o investimento estrangeiro direto chegou para dominar importantes setores de serviços e infra-estrutura que são não-comercializáveis e, portanto, estão indisponíveis para exportação;

- os grupos empresariais de capital brasileiro retiveram a hegemonia nos setores industriais de baixo valor agregado (commodities, como minerais não-metálicos, mineração, papel e polpa, aços e metalurgia) e não-comerciáveis (construção e moradia, serviços de transporte).

Nessas circunstâncias, não devem surpreender os efeitos negativos do regime macroeconômico da década de 90 sobre o domínio econômico do SNIB. Dois estudos empíricos comprovam isso em conexão com a estrutura, estabelecida na seção anterior, de cooperação, aprendizado e capacidades de inovação incorporadas.

O primeiro é o trabalho de Lemos et al. (2003) sobre as capacidades inovadoras da rede de fornecedores da Fiat em Minas Gerais. Ele mostra que:

- em contraste com a 'mineirização' da indústria de autopeças, lançada pela Fiat em 1986, ao longo de toda a década de 90 houve uma crescente 'italianização' da indústria de autopeças em Minas Gerais. Isso aconteceu porque a Fiat estimulou a entrada de fornecedores com os quais ela se relacionava há muito tempo na Itália. Como resultado, em uma amostra de 42 fornecedores dessa empresa entrevistados em 1994, 81\% eram nacionais; em outra amostra, de 20 entrevistados em 2000, 60\% eram empresas subsidiárias de fornecedores globais;

- apesar da boa disponibilidade de grupos locais de pesquisa em engenharia mecânica, a interação entre eles e a cadeia de suprimento local da Fiat é muito fraca. Um bom motivo para isso pode estar no fato de que cerca de $60 \%$ dos entrevistados na pesquisa supracitada consideram seus laboratórios de P\&D in-house fora do país como a principal fonte de informações relacionadas com atividades inovadoras;

- as atividades de co-projetos são praticamente inexistentes no Brasil, exceto nos casos em que a adaptação do componente às condições locais é necessária. Por isso, é muito baixa a difusão dos efeitos benéficos (spill-over) para o sistema local de inovação, uma vez que não se espera que os fornecedores locais tenham capacidade inde- pendente para desempenhar atividades de projeto nem que sejam, ao mesmo tempo, capazes de resolver problemas em conjunto com a montadora;

- existem indícios de falta de cooperação entre as empresas concorrentes, entre os fornecedores de segundo e terceiro escalões e entre eles e os fornecedores de matériasprimas e equipamentos. Somente dois aspectos da cooperação parecem ter aumentado de intensidade: o intercâmbio de informações e testes para o desenvolvimento e a melhoria de produtos. Essa maior cooperação parece estar relacionada com a busca da qualidade nos insumos, equipamentos e pessoal (por meio de treinamento);

- as atividades de P\&D quase desapareceram nesse setor na região: somente 18 fornecedores da Fiat têm patentes registradas no Brasil. Em 2000, o total de patentes era de 87 , em sua maioria de conteúdo simples; antes da liberalização econômica e da emergência do carro global, o Departamento de Engenharia da Fiat em Minas Gerais empregava quase 400 pessoas. Em 2000, o departamento tinha encolhido para menos de 100 funcionários;

- o fato de os principais laboratórios de P\&D estarem fora do país é decisivo para a baixa interação entre os agentes com respeito ao desenvolvimento de capacidades tecnológicas. Além disso, a debilidade dos mecanismos de transferência de tecnologia entre setores ou intra-setorialmente, vertical ou horizontalmente, tem comprometido a intensidade de efeitos benéficos e a sua difusão.

O segundo estudo que mostra os efeitos negativos do regime macroeconômico da década de 90 (SZAPIRO, 2003) traz dados do setor de telecomunicação, o qual está no cerne do PTE das TICs, e foi muito elogiado como uma história de sucesso do SNIB nos anos 80 (HOBDAY, 1990; PESSINI, 1986). Ele mostra que

as reformas estruturais da década de 1990 provocaram grande confusão no arranjo de Campinas, eliminando empresas e abolindo vínculos cooperativos entre instituições. Como conseqüência desses problemas, os processos de aprendizado acumulado no passado foram colocados em risco. Existem sérias dúvidas quanto à possibilidade de manutenção do desenvolvimento da tecnologia local. Os processos de liberalização do comércio e a desregulamentação promoveram, assim, desarticulação e destruição de ativos intangíveis de empresas e instituições, afetando profundamente suas competências básicas (SZAPIRO, 2003, p. 496, tradução nossa). 
Quanto à liberalização do comércio, a autora comenta que, embora não tenha provocado mudanças importantes na estrutura da indústria de equipamentos de telecomunicações, de um lado afetou significativamente o desenvolvimento de estratégias e da capacidade das empresas de capital nacional, reduzindo seu desenvolvimento tecnológico interno; e, de outro, as subsidiárias de multinacionais que estavam no Brasil antes do início da década de 90 ampliaram cada vez mais suas capacidades industriais e tecnológicas a partir de suas sedes e de outras subsidiárias do mesmo grupo.

No que diz respeito à privatização, Szapiro (2003) ressalta que: ocorreu um aumento considerável da parcela do setor de telecomunicações no déficit comercial do complexo eletrônico (alcançando mais de 40\% em 1999); houve uma mudança nas atividades conduzidas pelo Centro de Pesquisa e Desenvolvimento (CPqD), ${ }^{15}$ que reduziu o número de projetos de pesquisa que costumava empreender e aumentou a parcela de atividades de consultoria e assistência técnica de curto prazo como uma estratégia de sobrevivência.

A forte dependência das subsidiárias de empresas multinacionais de suas matrizes no estrangeiro tornou-se um inibidor para o fluxo de conhecimento e interação com as instituições educacionais locais. De acordo com a pesquisa de Szapiro (2003, p. 491, tradução nossa):

Os motivos dados pelas subsidiárias multinacionais para interagir/cooperar com outras instituições são a qualificação e o treinamento de recursos humanos e a comercialização dos produtos (o caso de $80 \%$ das empresas). Para elas, a cooperação destina-se a apoiar o treinamento de pessoal e a facilitar a comercialização dos produtos. Por outro lado, todas as empresas de capital nacional declararam que o acesso à tecnologia é o principal motivo para a interação com outras instituições [...] É interessante observar que o comportamento das subsidiárias difere daquele que prevalecia no final dos anos 70 e 80 . Nesse período, alguns projetos foram desenvolvidos entre as subsidiárias multinacionais e o CPqD, como resultado das políticas implementadas no setor.

Szapiro cita ainda Souza e Garcia (1999) para mostrar uma mudança no motivo pelo qual as empresas buscavam essa localização específica. Aquelas que tinham se instalado em Campinas antes da década de 90 afirmaram que tinham escolhido o local pela facilidade de acesso às instituições de P\&D e educação. Já para as que chegaram lá na segunda metade daquela década, a escolha foi feita com base na disponibilidade de recursos de mão-de-obra e de um sistema bem desenvolvido de estradas. ${ }^{16}$

Saindo de casos como o dos fornecedores da Fiat em Minas Gerais e o das telecomunicações em São Paulo, podem-se encontrar situações em que a estrutura geral da política econômica anteriormente mencionada teve impactos contraditórios nas capacidades inovadoras dos microfundamentos do SNIB, como é o caso dos arranjos produtivos locais - APLs. ${ }^{17}$ De um lado, a sobrevalorização da moeda local provocou o acirramento da concorrência de fora do país, que foi alimentada pela redução das tarifas sobre mercadorias importadas, de outro, a desvalorização cambial favoreceu a modernização de suas fábricas por meio da importação de bens de capital a custos relativos mais baixos. No caso da indústria têxtil e de roupas do Vale do Itajaí estudado por Campos, Cário e Nicolau (2003), a importação de equipamentos não produziu efeitos internos capazes de incentivar diretamente as interações para o aprendizado inovador, afora a incorporação das novas tecnologias compreendida em máquinas e equipamentos.

Em outros casos, foram encontrados indícios de melhoria nas capacidades de inovação de empresas e organizações locais, embora específicas e restritas a alguns elementos do respectivo arranjo. Assim, os APLs de calçados do Rio Grande do Sul (VARGAS; ALIEVI, 2003), de têxteis e roupas do Vale do Itajaí e de metal-mecânica do Espírito Santo (VILLASCHI; LIMA, 2003) foram incentivados a melhorar sua capacidade de atendimento às demandas dos clientes no curto prazo. Deve-se enfatizar que, na maioria dos casos, essa qualificação ficou restrita à inovação do processo.

Outros estudos empíricos podem ser usados para ilustrar a perversidade das políticas econômicas liberais praticadas no Brasil ao longo de toda a década de 90. De Paula, Porcile e Scatolin (2003), por exemplo, mostraram que, no caso do APL da soja, no Paraná, duas alterações tiveram efeito negativo sobre suas capacidades tecnológicas: primeiro, a mudança nas estratégias de P\&D pela principal fonte de inovação, a Empresa Brasileira de Pesquisa Agropecuária - Embrapa, que não permite mais a co-propriedade de novas variedades; segundo, as modificações na legislação que regula a produção de novas variedades e que assegura a apropriação privada de inovações por meio de patentes.

Essas duas mudanças quase liquidaram o sistema de cooperação para a proposta de novas variedades, o qual viabilizava as estratégias da Embrapa para o desenvolvi- 
mento de sementes por meio de vínculos estreitos com pequenos e médios produtores e cooperativas. Igualmente se deve observar que essas mudanças ocorreram no momento em que os produtores multinacionais de sementes de soja começaram a entrar maciçamente no Brasil. Como se indicou nos casos dos fornecedores da Fiat e das telecomunicações, isso também significou uma transferência das capacidades de inovação em direção aos laboratórios das multinacionais em seus países de origem.

\section{Domínio Institucional}

Como se ressaltou na segunda parte deste artigo, em um mundo caracterizado por atividades inovadoras (centradas em diferentes formas e conteúdos de conhecimento adquiridos por meio de diversas fontes e meios de aprendizado), a incerteza é um aspecto importante da vida econômica. Por esse motivo, a existência de ambientes institucionais em diferentes níveis (de uma empresa específica, de um grupo de empresas ou de um país) se torna um dos componentes centrais de um sistema de inovação. Nesse mundo, então, as instituições movem-se para além das características de rotinas e direcionam a vida diária de modo a funcionar também como uma estrutura para a mudança.

Mytelka e Smith (2001) enfatizam que o reconhecimento da necessidade dessa estrutura para a mudança pode ser encontrado de forma cada vez mais intensa, ao longo de toda a década de 90, nas políticas delineadas nos países da Organização para a Cooperação e o Desenvolvimento Econômico - OCDE. Nessa mesma direção, Edquist (1997, p. 16) indica que a abordagem do SNI foi usada como

um meio para o estudo das inovações, como uma estrutura conceitual para a elaboração de políticas do governo e como base para a formulação de estratégias de inovação de empresas.

Edquist (2001) vai ainda além e destaca que a abordagem do sistema nacional de inovação se estabeleceu em um tempo relativamente curto e começou a ser usada amplamente, não somente no meio acadêmico, mas também no estabelecimento de políticas de inovação. De maneira semelhante, Miettinen (2002) reconhece que esse conceito contribui para aproximar pesquisadores, burocratas e servidores civis que o fizeram funcionar como uma metáfora de fronteira da organização.

Uma pergunta que se deve fazer, então, é por que, no Brasil, a abordagem do SNI não foi além dos estudos so- bre inovação; ou por que, como estrutura conceitual, não foi sequer considerada na elaboração de políticas governamentais nem como base para a formulação das estratégias de inovação das empresas.

O trabalho dos uruguaios Arocena e Sutz (2002) pode ajudar a lançar luz sobre essas questões. Os pesquisadores indicam que a abordagem do SNI não pode ser vista como trivial, apesar de ele ser reconhecido como um conceito político e apesar de a realidade por ele descrita poder ser submetida a esforços deliberados no sentido de mudança, com a esperança razoável de se alcançar o que é pretendido. Isso porque, mesmo para ser tomado como um conceito político, ele precisa de atitudes sociais com respeito a transformações globais.

Segundo eles,

as atitudes sociais com respeito às transformações globais pertencem às questões que merecem atenção especial na abordagem de Hirschman: 'O nosso diagnóstico é que simplesmente países falham em aproveitar seu desenvolvimento potencial, porque, por motivos em grande parte relacionados com a sua imagem de mudança, eles acham difícil tomar as decisões necessárias para o desenvolvimento, na quantidade e na velocidade necessárias' (HIRSCHMAN, 1958; apud AROCENA; SUTZ, 2002, p. 15, tradução nossa).

Poder-se-ia dizer, então, que uma importante restrição a um ambiente institucional do SNIB melhor sintonizado na década de 90 foi a falta de visão (Quadro 1). De acordo com Fransman (2002, p. 8, tradução nossa),

[...] A "visão", ou estrutura cognitiva, consiste de um conjunto inter-relacionado de crenças, incorporadas em suposições e expectativas, que servem para fazer o mundo parecer inteligível e, portanto, orientar as tomadas de decisão.

Como, na década de 90, a imagem dominante entre as autoridades econômicas no Brasil estava ligada à competitividade com base nas dotações de fatores (sobretudo recursos naturais e mão-de-obra barata), não surpreende o fato de pouco ter sido feito com relação às oportunidades e restrições que emergiram com o PTE da TIC. Isso não quer dizer, porém, que o assunto tenha permanecido totalmente ausente da agenda do governo.

Contrariamente ao que aconteceu com a abordagem do SNI (que foi objeto de apenas alguns trabalhos acadêmicos e nunca foi além de seminários ou de prateleiras de bibliotecas), a necessidade de financiamento apropriado 
da inovação e do desenvolvimento tecnológico e uma certa conscientização dos desafios da 'sociedade da informação' podem ser encontradas em diferentes níveis do debate público.

Esses são certamente os casos das tentativas de criação de fundos com destinação específica para o financiamento de projetos de ciência e tecnologia - C\&T. A primeira ocorreu na Constituição de 1988, que permitiu que os governos estaduais comprometessem certo porcentual de suas receitas para financiamento de C\&T. A segunda foi o movimento entre autoridades do governo federal, com o compromisso de apoio de membros do parlamento (em número restrito) e da comunidade empresarial, no sentido de garantir financiamento para P\&D em 13 áreas econômicas ${ }^{18}$ e para a infra-estrutura de C\&T das universidades.

Apesar de suas vitórias políticas, essas tentativas não apresentaram resultados substanciais na década de 90 . Por um lado, embora muitos Estados tenham adotado em suas constituições o princípio do comprometimento de fundos para C\&T, a letra da lei não teve uma resposta prática. $\mathrm{Na}$ maioria dos casos, os montantes que aparecem nos orçamentos dos Estados não se transformam em recursos financeiros para projetos de pesquisas durante o ano. "Quando é necessário o controle orçamentário, as primeiras despesas a serem sacrificadas são as que têm menos apelo público" - esse é um dito comum entre os que são responsáveis pela manutenção do equilíbrio das finanças públicas.

Por outro lado, o projeto do Ministério da Ciência e Tecnologia de garantir financiamento estável para o setor no âmbito federal criou sua primeira conta (a do petróleo) em 1999. Assim, a eficácia desse projeto, com respeito a seus principais objetivos (financiamento estável, promoção de laços mais estreitos entre universidade e empresas, promoção de pesquisa em C\&T, priorização no uso de recursos, monitoramento de resultados), só poderá ser avaliada em um cenário posterior ao da década aqui analisada.

Também foram feitas tentativas para aumentar a conscientização sobre desafios e oportunidades que emergem em tempos de mudança do PTE. Uma vez mais, trabalhou-se no âmbito do Ministério da Ciência e Tecnologia:

para reforçar o desenvolvimento da Nova Economia em nosso país, devemos incentivar a utilização dessas tecnologias nas empresas brasileiras, o que é a meta do Programa Sociedade da Informação - um dos mais ambiciosos programas do plano de desenvolvimento
'Avança Brasil' e o resultado de esforços inicialmente empreendidos em 1996 pelo Conselho Nacional de Ciência e Tecnologia. Seu principal propósito é estabelecer os fundamentos de um projeto estratégico em toda a nação para integrar e coordenar o desenvolvimento e emprego de tecnologias avançadas de computação, comunicação e informação e suas aplicações na sociedade. Este esforço permitirá ao governo promover a pesquisa e a educação, bem como assegurar que a economia brasileira seja capaz. de competir no mercado mundial (Embaixador Ronaldo Mota Sardenberg, Ministro de Estado da Ciência $e$ Tecnologia, em 13 de setembro de 2000, no lançamento de Sociedade da informação no Brasil: Livro verde).

Apesar das boas intenções do ministro e de alguns de seus colegas em diferentes esferas do governo, do mundo acadêmico e do empresariado, o lançamento retardado de um programa focado na sociedade da informação no Brasil teve o mesmo destino dos outros relacionados ao anteriormente elogiado "Avança Brasil": falta de financiamento apropriado e de continuidade, devido ao baixo compromisso político nas esferas de governo em que as decisões eram tomadas.

Deve-se ressaltar, porém, que essa lacuna entre o pensamento dos que estão comprometidos com a ciência e a tecnologia no Brasil e o dos que de fato gerem a política econômica com uma abordagem pragmática de curto prazo é recorrente na história recente. De um lado, como observa Jaguaribe (1987), ela se fez presente muitas vezes no processo de industrialização do país, quando o governo precisou tomar uma posição sobre o modelo a ser adotado: aquele baseado na tecnologia incorporada importada ou aquele voltado para o fortalecimento da capacidade tecnológica interna em médio e longo prazos.

Por outro lado, como destacou Piragibe (1988), isso também está enraizado na história da política da informática no Brasil. Nos anos 80 , houve um debate acirrado no governo entre os que desejavam proteger o mercado interno de computadores, como uma maneira de promover as capacidades da indústria e da inovação nesse setor, e os que desejavam evitar a retaliação dos Estados Unidos, que ameaçavam fechar seu mercado a commodities como suco de laranja, sapatos, etc.

\section{Domínio Tecnológico}

Dadas as restrições gerais impostas ao SNIB pela liberalização, privatização e pelas idéias por detrás da política econômica ao longo de toda a década de 90 e levando em 
consideração a estrutura institucional geral acima mencionada, não surpreende o fraco domínio tecnológico do SNIB.

Mesmo quando não explicitamente mencionado, os dados coletados aqui devem ser vistos de uma perspectiva que leve em consideração as características tecnológicas do novo paradigma (conforme indicado no Quadro 1), ou seja, conhecimento e comunicação, vinculados com a mente humana; conectividade pessoa-a-pessoa; sustentabilidade pessoal, física e psicológica.

Além disso, os dados vão além de um discurso que, muitas vezes, é uma resposta consciente de pessoas dos setores acadêmico, governamental e privado. Isso, todavia, não é suficiente, por si só, para romper elementos rígidos como os indicados por Hämäläinen (1999) e Perez (1997), mencionados anteriormente.

Assim, por exemplo, o início da década de 90 foi marcado pela introdução de diversas iniciativas nacionais na área de computação, sob os auspícios do Ministério de Ciência e Tecnologia, como: ${ }^{19}$

- a Rede Nacional de Pesquisa - RNP, destinada à implementação da Internet para propósitos educacionais e de pesquisa no país inteiro;

- o Programa Temático Multinstitucional em Ciência da Computação - ProTeM-CC, destinado a estruturar e apoiar um modelo de pesquisa por meio de um consórcio entre entidades acadêmicas e o setor privado;

- o Programa Nacional de Software para Exportação Softex, destinado a estruturar e coordenar um esforço nacional para fomentar significativamente a exportação de softwares produzidos no Brasil;

- o Sistema Nacional de Processamento de Alto Desempenho - Sinapad, destinado a estabelecer centros para a prestação de serviços computacionais superiores no país.

Essas iniciativas, entretanto, não tiveram a flexibilidade e a estabilidade necessárias para promover a mudança, sobretudo em tempos de troca de PTE. Por isso, não surpreende que, em meados dessa década, os problemas de institucionalização e financiamento tenham sido suficientes para fazer as agências governamentais mudarem seus objetivos com respeito ao novo PTE.

Algumas dessas respostas (como sociedade da informação e os fundos setoriais de C\&T) somente se tornaram efetivas na década seguinte. Apesar das tentativas de superar os problemas institucionais e financeiros relativos a ciência, tecnologia e inovação em geral e das iniciativas especificamente enfocadas no PTE corrente, primeiro será preciso constatar sua eficácia para, depois, avaliá-las.
Por esse motivo, os elementos que devem ser levados em consideração nas análises de domínio tecnológico do SNIB são aqueles relacionados com a disponibilidade dos serviços de educação, tecnologia e treinamento. Quanto ao sistema educacional, apesar do maior número de alunos que freqüentam as escolas em todos os níveis (inclusive pós-graduação), seu desempenho qualitativo não apresenta padrões razoáveis. ${ }^{20}$

O número de alunos universitários aumentou de mais de 1,5 milhão, no começo da década de 90 , para perto de 3 milhões em 2000 (Instituto Nacional de Estudos e Pesquisas Educacionais - Inep). É importante observar que a maioria desses alunos está matriculada em escolas privadas. Enquanto o número de instituições públicas nesse nível do sistema educacional se estabilizou em torno de 200 desde os anos 80, no setor privado aumentaram de cerca de 650, em 1990, para duas vezes esse número em 2000.

Como resultado, a proporção de alunos matriculados em escolas privadas está perto de $75 \%$ do total na educação superior no Brasil. Um exame mais detido mostra dois complementos importantes desses números. Por um lado, há concentração em áreas de conhecimento em que o investimento em laboratórios e equipamentos é mais baixo (sobretudo nas humanidades). Por outro, tomando-se como representativos os números das instituições que oferecem cursos em engenharia mecânica e elétrica, as escolas públicas (em sua maioria, mantidas pelo governo federal) respondem por mais de $60 \%$ do total de matrículas nessas áreas no país.

O número de cursos de pós-graduação também aumentou nos anos 90. No final dessa década, havia perto de 2.700 cursos de mestrado e doutorado no país. Desses, somente cerca de 300 em engenharia. Essa baixa participação de engenheiros com preparação em pesquisa deve ser considerada como uma indicação de que não se pode esperar, no SNIB, muita interação do tipo que ajuda a codificar o conhecimento tácito, conforme sugerido por Nonaka e Takeuchi (1995).

Além disso, deve-se enfatizar a crítica geral que é feita à rigidez prevalecente em cursos e disciplinas oferecidos em grande parte das instituições de educação superior no SNIB. Na maioria das entrevistas feitas com agentes de arranjos produtivos locais - APLs, essa rigidez é ressaltada por acadêmicos, autoridades, gerentes e empresários como um gargalo para o estreitamento dos vínculos entre a educação superior e a sociedade, de maneira geral, e as empresas, mais especificamente. 
Ademais, a "necessidade de mudanças na estrutura institucional para assegurar que, no longo prazo, os aspectos criativos e críticos da pesquisa acadêmica possam sobreviver" (LUNDVALL, 2002) encontra fundamentos frágeis no SNIB. Salários congelados, condições insatisfatórias de trabalho e financiamento escasso e instável fizeram do ensino e da pesquisa atividades muito pouco atraentes no Brasil ao longo de toda a década de 90. Não surpreende que, em muitas escolas públicas de educação superior, o número de professores substitutos ${ }^{21}$ tenha aumentado durante esse período, alcançando, em muitos departamentos de universidades federais, mais de $25 \%$. Isso aumenta o volume do trabalho burocrático a ser realizado pelos demais membros do departamento, o que os mantém cada vez mais distantes das salas de aula e dos laboratórios, da criatividade e da crítica necessárias para mudar a estrutura institucional.

O quadro não se mostra melhor quando se passa da educação formal e da pesquisa para os serviços de capacitação e inovação. Os levantamentos feitos em cerca de $20 \mathrm{APLs}^{22}$ mostra que, mesmo nos casos em que esses serviços são prestados por organizações especificamente concebidas para responder às especificidades das pequenas e médias empresas locais, a lacuna entre o que é oferecido e o que é usado pode permanecer grande.

Isso acontece mesmo em se tratando de serviços nãosofisticados de tecnologia ou inovação. No caso da organização do setor de calçados no Estado da Paraíba, por exemplo, existe uma lacuna entre os serviços que são oferecidos pelo departamento local do Senai e o baixo nível de demanda para esses serviços, sobretudo da parte de micro e pequenas empresas.

\section{COMENTÁRIOS FINAIS}

O debate da 'década perdida' tem estado presente na agenda brasileira desde os anos 80. Nessa década, o país perdeu oportunidades de: renegociar sua dívida de uma maneira diferente da abordagem da "dívida não é para ser paga, mas para ser rolada", usada por autoridades pragmáticas na esteira da crise mexicana de 1982; controlar a hiperinflação em 1986, ocasião em que o Plano Cruzado foi atingido em seus fundamentos visto que a estabilização dos preços a baixos custos sociais se tornou uma questão de vida ou morte para os políticos do partido no poder; ter uma estrutura institucional mais estável e flexível sob a Constituição de 1988, que acabou se tornando uma colcha de retalhos de questões sociais, econômicas e políticas conflitantes.

Não obstante, muitos estudos sobre a economia da inovação no país nos anos 80 (entre outros: EVANS; TIGRE, 1989a; 1989b; HOBDAY, 1990; HEWITT, 1988; PESSINI, 1986; SCHMITZ; CASSIOLATO, 1992; TIGRE; FERRAZ, 1989; VILLASCHI, 1992) mostram que, apesar de todos os problemas em seu cenário macroeconômico, o Brasil teve um desempenho razoável em muitas áreas básicas do PTE das TICs. Apesar de problemas aqui e ali na política de informática, os resultados em telecomunicações e em outras áreas (automação dos bancos, petróleo e aeronáutica, por exemplo) indicavam a existência de capacidades internas de inovação que poderiam ajudar o país a ter uma postura correta em sua marcha para um novo PTE.

Na década de 90, o debate da 'década perdida' perdeu força por haver quase uma aceitação total, entre as autoridades governamentais, de que, uma vez conquistada a estabilidade de preços e desregulamentados os mercados, o país retornaria ao caminho do crescimento que caracterizou sua economia na maior parte do século XX. A estabilidade de preços foi alcançada em 1994, mas a um preço muito alto para a estabilidade econômica, conforme enfatizado por Coutinho (2003) e outros.

O presente trabalho buscou apresentar dados que indicam que o culto exagerado ao mercado, que esteve no cerne da política econômica do Brasil por toda a década de 90, tem colocado em risco as chances de estabilidade econômica do país no médio e longo prazos. Isso porque não foram reconhecidas questões consideradas cruciais quando um país deseja desempenhar um papel ativo nos fluxos mundiais de bens, serviços e conhecimento que são importantes no contexto do PTE da TIC.

Características básicas do novo PTE, como conhecimento e comunicação vinculados com a mente humana; processos de produção intensivos em informação; redes de produção; serviços empresariais intensivos em conhecimento; informações, coordenação e regulamentação do governo; visão, entre outras, foram deixadas de lado no debate público do país e na agenda do governo.

Nessas circunstâncias, a inserção do país na nova fase de internacionalização das relações econômicas e sociais - a assim chamada globalização - reduziu-se ao aumento de sua parcela no mercado de commodities de baixo valor agregado, como soja, aço, celulose, sapatos, etc. Foi como se os sinais do que está acontecendo em outros países (especialmente naqueles da OCDE) não passassem de uma 
abstração a que uma formação socioeconômica com as dotações dos recursos naturais do Brasil continental não devesse prestar atenção.

A necessidade de manter-se a par do que estava sendo discutido sobre aprendizado e conhecimento em uma era que já não era mais apenas uma perspectiva só foi reconhecida por uma comunidade muito restrita de acadêmicos, empresários, políticos e autoridades governamentais. Eles certamente não tinham como fazer o país acompanhar o que Tuomi (2001) chama de duas ondas, que dominaram o debate sobre sociedade do conhecimento na década de 90.

A primeira onda focava questões já presentes no debate dos anos 80 (competitividade, crescimento econômico, acesso, regulamentação, privacidade, segurança e direitos de propriedade intelectual), com o acréscimo da preocupação emergente dos ricos e dos pobres em informações.

A segunda onda identifica-se com as preocupações expressas por Ducatel e seus colaboradores:

Reconhece-se agora que a relação entre mudança tecnológica e transformação social é complexa, e agora também está desnudada a falsidade da noção simplista de que as mudanças tecnológicas têm efeitos sociais, os quais, por sua vez, podem ser controlados de maneira simples por meio de políticas apropriadas [...] Isso acarreta uma maior complexidade para a formulação de políticas: não é suficiente desenvolver e implementar politicas apropriadas de tecnologia separadamente. As políticas de tecnologia e as políticas sociais precisam ser desenvolvidas de maneira complementar e visar objetivos complementares. É necessário, se desejamos que a 'sociedade' de sociedade da informação seja algo mais que um artifício retórico, desenvolver uma avaliação mais sofisticada dessas questões sociais. (DUCATEL et al., 2000 apud TUOMI, 2001, p. 8, tradução nossa)

Isso, por si só, deveria ser suficiente para justificar as posições assumidas neste artigo. Essas não devem, de maneira alguma, ser consideradas frutos de pensamentos fantasiosos com relação às janelas de oportunidades que estão abertas ao SNIB sob o PTE das TICs.

$\mathrm{Na}$ verdade, o que o trabalho tenta enfatizar está em sintonia com a maneira como Arocena e Sutz (2002, p. 6, tradução nossa) vêem a aplicabilidade do conceito do SNI no Sul:

Ao contrário [do que acontece no Norte, onde o conceito se fundamenta em conclusões empíricas], no Sul ele é mais um conceito ex-ante, porque o comportamento socioeconômico relativo à inovação em nível nacional raramente é sistêmico.

Nessa perspectiva, pode-se dizer que este artigo assume uma posição semelhante àquela de Freeman e Louçã (2001, tradução nossa). Eles citam Charles Dickens, em Um conto de duas cidades:

Foi o melhor dos tempos, foi o pior dos tempos; foi a idade da sabedoria, foi a idade da tolice; foi a época da fé, foi a época da incredulidade; foi a estação da Luz, foi a estação das Trevas; foi a primavera da esperança, foi o inverno do desespero; tínhamos tudo diante de nós, não tínhamos nada diante de nós.

Os pesquisadores concluem seu livro afirmando que o fundamental é escolher. Aqui, a escolha recaiu sobre questões que a formação socioeconômica brasileira deve enfrentar em três domínios autônomos e interdependentes, que podem caracterizar um SNI em face dos desafios e das oportunidades sob o PTE das TICs: ${ }^{23}$ o domínio tecnológico (que disponibiliza a tecnologia), o domínio econômico (que assegura a viabilidade e sustentabilidade da inovação) e o domínio institucional (que possibilita a inovação).

\section{NOTAS}

Baseado em um estudo apresentado em The First Globelics Conference: Innovation Systems and Development Strategies for the Third Millenium, Rio de Janeiro, de 2 a 6 de novembro de 2003. O autor agradece os proveitosos comentários feitos na época, especialmente os de Martin Fransman, Pekka Ylla-Antilla e Tarmo Lemola. Registra também seus agradecimentos à equipe de tradutores do BID por colaboração na tradução do texto originalmente escrito em inglês.

1. Para um exame dos diferentes aspectos da abordagem dos sistemas de inovação, ver Lundvall et al. (2001) e Edquist (1997). Para comentários críticos sobre a abordagem, ver Edquist (2001). Miettinen (2002) destaca as críticas ao conceito, sobretudo no tocante às maneiras como ele foi incorporado no discurso europeu de políticas tecnológicas.

2. Ver, por exemplo, Cortada (2000).

3. Freeman e Louçã (2001, p. 301) lembram que até o presidente do Banco Central dos Estados Unidos, Alan Greenspan, "tem falado com freqüência do 'novo paradigma', referindo-se especificamente a computadores, telecomunicações e Internet, como uma fonte da notável explosão de crescimento na economia dos Estados Unidos na década de 90 ".

4. Em outro estudo (VILLASCHI, 2004), exploro características alternativas do paradigma técnico-econômico da TIC indicadas por Castells (2000), Drucker (2001) e Tuomi (2001).

5. É importante, porém, ter em mente que, nas teorias que formam o cerne da economia ortodoxa, presume-se que os agentes racionais façam escolhas com base em um volume dado de informações. O único tipo de aprendizado permitido é o acesso dos agentes a novas fontes de informação. 
6. Os autores observam que esse tipo de conhecimento se tornou cada vez mais importante porque existe uma tendência geral em direção a uma base de conhecimento mais complexa, com novos produtos que normalmente combinam muitas tecnologias, cada uma delas enraizada em disciplinas científicas diferentes. Isso torna o acesso a fontes diversas de conhecimento ainda mais essencial.

7. Isso deveria ser objeto de análise mais detalhada para os que estão trabalhando na perspectiva de uma nova ordem internacional em tempos de TICs. Como informação e conhecimento se referem mais do que nunca a relações de poder, os ricos e os pobres, tanto entre países como dentro de cada país, não podem ser considerados um tema marginal para os que estão pesquisando oportunidades e restrições na nova/ próxima sociedade/economia/paradigma.

8. Nesse contexto, o Centro do Programa de Especialização finlandês pode ser visto como um modelo em matéria de facilitação do acesso a quem sabe onde encontrar o que é relevante e como traduzir o que é encontrado de maneira participativa para a empresa.

9. Johnson e Lundvall (2001) também ressaltam que, contrariando a difusão dos efeitos benéficos livres que são presumidos na economia ortodoxa, o acesso ao know-why científico, em todas as circunstâncias, depende do investimento em atividades de P\&D e em ciência.

10. No contexto de países em desenvolvimento, isso é essencial mesmo quando não se está lidando com equipamentos de processo complexo. Diante de uma força de trabalho com pouca qualificação, o treinamento é crucial para que o conhecimento incorporado em máquinas e equipamentos tenha algum impacto econômico.

11. Os eventos ocorridos antes de 11 de setembro de 2001 e as reações posteriores ilustram muito bem essa interpretação.

12. Aqui, deve ser entendido em diferentes escalas de espaço (local, regional, nacional, supranacional) e como outras formas de reunião social (étnica, religiosa, profissional, etc.).

13. Essa grave debilitação dos grupos empresariais nacionais transferiu o controle de mais de 200 importantes empresas para corporações estrangeiras. Pelo menos 50 delas eram empresas públicas que depois se tornaram subsidiárias de capital totalmente fechado.

14. De acordo com o Instituto de Estudos para o Desenvolvimento Industrial - IEDI, entre 1994 e 1998 a presença do controle de investidores estrangeiros (porcentagem de vendas das 20 maiores empresas) movimentou de $55 \%$ a $79 \%$ em autopeças; de $34 \%$ a $79 \%$ em produtos eletrônicos; de $69 \%$ a $83 \%$ em informática; de zero a $75 \%$ em telecomunicações e de $44 \%$ a $73 \%$ em bens de capital.

15. Um marco importante no esforço para o estabelecimento de um modelo nacional e independente para o setor de telecomunicação, o CPqD é um o centro de P\&D, criado pela estatal Telebrás nos anos 70 , com o objetivo de se tornar um referencial no país para os projetos de pesquisa e desenvolvimento de equipamentos e serviços nesse setor.

16. Nos termos definidos na segunda parte deste artigo, é como se o SNIB estivesse regredindo do novo para o antigo PTE.

17. Para uma discussão do conceito e da abordagem, ver Villaschi e Campos (2002).

18. Petróleo, infra-estrutura, energia, recursos hídricos, transportes, minerais, espaço, telecomunicações, tecnologia da informação, saúde, aeronáutica, agroindústria e biotecnologia.

19. Para detalhes sobre esses programas e outras iniciativas sobre a sociedade da informação no Brasil, ver < http://www.socinfo.org.br/ livro_verde/ingles/implem.htm>.

20. É importante ter em mente que mais de $25 \%$ dos alunos que freqüentam a escola primária no Brasil levam sete anos para concluir os primeiros cinco anos do sistema educacional. Mais relevante ainda é o fato de que um número substancial dos que concluem a educação primária não exibe a competência apropriada em língua portuguesa e matemática básica.
21. Só podem ser contratados para um período que não exceda dois anos.

22. Ver: 〈http://www.ie.ufrj.br/redesist>.

23. Como Antilla e Lemola (2003) destacaram, tais desafios e oportunidades devem ser enfrentados com um alto grau de destruição criadora para o país beneficiar-se das janelas abertas pelo novo paradigma, como fez a Finlândia. Um desafio adicional para o Brasil seria, então, romper com seus últimos 20 anos de destruição não-criadora das capacidades institucionais e inovativas.

\section{REFERÊNCIAS BIBLIOGRÁFICAS}

ALI-YRKKÖ, J. Nokia's network - gaining competitiveness from co-operation. Helsinque: Taloustieto, 2001.

ANDERSEN, E.; LUNDVALL, B-Å. Small national systems of innovation facing technological revolutions an analytical framework. In: FREEMAN, C.; LUNDVALL, B-Å. (Ed.). Small countries facing the technological revolution. London: Pinter, 1988.

ANTILLA, P.; LEMOLA, T. Transformation of innovation system in a small country - the case of Finland. In: GLOBELICS CONFERENCE, 2-6 nov. 2003, Rio de Janeiro. Anais... Rio de Janeiro, 2003.

AROCENA, R.; SUTZ, J. Innovation systems in developing countries. In: DRUID Working Paper 2002-5, 2002. Disponível em: $<$ http://www.druid.dk>.

ARROW, K. The economic implications of learning by doing. Review of Economic Studies, v. XXIX, n. 80, p. 155-73, 1962.

CASTELLS, M. The information age economy, society and culture. 2. ed. Oxford: Blackwell, 2000.

CAMPOS, R.; CÁRIO, S.; NICOLAU, J. Textile and clothing local productive system in the Itajai Valley: local capabilities and partial interactive learning. In: CASSIOLATO, J.; LASTRES, H.; MACIEL, M. (Ed.). Systems of innovation and development - evidence from Brazil. Cheltenham: Edward Elgar, 2003.

CASSIOLATO, J.; LASTRES, H.; MACIEL, M. (Ed.). Systems of innovation and development - evidence from Brazil. Cheltenham: Edward Elgar, 2003.

COLEMAN, J. Social capital in the creation of juman capital. In: LESSER, E. (Ed.). Knowledge and social capital - foundations and applications. Woburn, MA: Butterworth-Heinemann, 2000.

CORTADA, J. Progenitors of the information age - the development of chips and computers. In: CHANDLER JR, A.; CORTADA, J. (Ed.). A nation trasformed by information. New York: Oxford University Press, 2000.

COUTINHO, L. Macroeconomic regimes and business strategies: an alternative industrial policy of Brazil in the wake of the $21^{\text {st }}$ century. In: CASSIOLATO, J.; LASTRES, H.; MACIEL, M. (Ed.). Systems of innovation and development - evidence from Brazil. Cheltenham: Edward Elgar, 2003.

DE PAULA, N.; PORCILE, G.; SCATOLIN, F. Strengthning and weakening local capabilities: the case of the local innovation system in the Paraná soybean agroindustrial sector. In: CASSIOLATO, J.; LASTRES, H.; MACIEL, M. (Ed.). Systems of innovation and development - evidence from Brazil. Cheltenham: Edward Elgar, 2003. 
DOSI, G. Technology and conditions of macroeconomic development. In: FREEMAN, C. (Ed.). Design, innovation and long cycles in economic development. New York: St. Martin's Press, 1984.

DOSI, G.; FREEMAN, C.; NELSON, R.; SILVERBERG, G.; SOETE, L. (Ed.). Technical change and economic theory. London: Pinter, 1988.

DRUCKER, P. The next society - a survey of the near future. Special Survey, The Economist, 3 nov. 2001.

DUCATEL, K.; WEBSTER, J.; HERRMANN, W. Information infrastructure or societies? In: (Ed.). The information society in Europe - work and life in an age of globalisation. Lanham: Rowman \& Littlefield, 2000.

EDQUIST, C. The systems of innovation approach and innovation policy: An account of the state of the art. In: THE NELSON AND WINTER DRUID SUMMER CONFERENCE, 12-15 jun. 2001, Aalborg, Dinamarca. Anais... Aalborg, 2001.

(Ed.). Systems of Innovation: Technologies, Institutions and Organizations. London: Pinter Publishers/Cassell Academic, 1997.

EVANS, P.; TIGRE, P. Estratégias de desenvolvimento de indústrias de alta tecnologia: análise comparativa da informática no Brasil e na Coréia do Sul. Revista Brasileira de Economia, Rio de Janeiro, FGV, v. 43, n. 4, p. 549-73, 1989a.

. Brasil e Coréia: para além dos clones. Novos Estudos Cebrap, São Paulo, Cebrap, v. 24, n. 1, p. 110-130, 1989b.

FRANSMAN, M. Telecoms in the Internet Age - from boom to bust to...? Oxford: Oxford University Press, 2002.

FREEMAN, C. Technology policy and economic performance lesson from Japan. London: Frances Pinter, 1987.

FREEMAN, C.; LOUÇÃ. As time goes by - from the Industrial Revolutions to the Information Revolution. Oxford: Oxford University Press, 2001

FREEMAN, C.; PEREZ, C. Structural crises of adjustment business cycles and investment behaviour. In: DOSI, G. et al. (Ed.). Technical change and economic theory. London: Pinter, 1988.

FUKYAMA, F. Trust: the social virtues and the creation of prosperity. London: Hamish Hamilton, 1995.

GERTLER, M. Tacit knowledge and the economic geography of context or the undefinable tacitness of being (there). In: THE NELSON AND WINTER DRUID SUMMER CONFERENCE, 12-15 jun. 2001, Aalbolg, Dinamarca. Anais... Aalborg, 2001.

HÄMÄLÄINEN, T. A techno-economic paradigma shift and the process of socio-institutional adjustment. In: SCHIENSTOCK, G.; KUUSI, O. (Ed.). Transformation towards a learning economy. Helsinque: Sitra, 1999.

HEWITT, T. Employment and skills in the electronics industry: the case of Brazil. Tese (Doutorado em Filosofia) - Universidade de Sussex, 1988

HOBDAY, M. Telecommunications in developing countries - the challenge from Brazil. London: Routledge, 1990.

JAGUARIBE, A. A política tecnológica e sua articulação com a política econômica: elementos para uma análise da ação do Estado. Rio de Janeiro, IEI/UFRJ, 1987. (Texto para discussão, n. 115).
JOHNSON, B.; LUNDVALL, B- $\AA$. Why all this fuss about codified and tacit knowledge? In: The DRUID WINTER CONFERENCE, 1820 jan. 2001, Aalborg, Dinamarca. Anais... Aalborg, 2001.

KUUSI, O. Growing and learning entrepreneurial networks as the focus of national innovation strategy. In: SCHIENSTOCK, G.; KUUSI, O. (Ed.). Transformation towards a learning economy: The challenge for the finnish innovation system. Helsinque: Sitra, 1999.

LEMOS, C.; PALHANO, A. Clustering in a backward region: the footwear productive system in Campina Grande. In: CASSIOLATO, J.; LASTRES, H.; MACIEL, M. (Ed.). Systems of innovation and development - evidence from Brazil. Cheltenham: Edward Elgar, 2003.

LEMOS, M.; CAMPOLINA, C.; BORGES, F.; CROCCO, M.; CAMARGO, O. Liberalization and local innovative capabilites: the Fiat supplier network in Minas Gerais. In: CASSIOLATO, J.; LASTRES, H.; MACIEL, M. (Ed.). Systems of innovation and development - evidence from Brazil. Cheltenham: Edward Elgar, 2003.

LUNDVALL, B. The university in the learning economy. In: DRUID Working Paper 2002-6, 2002. Disponível em: <http://www.druid.dk>

Innovation as an interactive process from user-producer interaction to the national system of innovation. In: DOSI, G. et al. (Ed.). Technical change and economic theory. London: Pinter, 1988.

Product innovation and user-producer interaction. Aalborg: Aalborg University Press, 1985.

LUNDVALL, B; JOHNSON, B; ANDERSEN, E.; DALUM, B. National systems of production, innovation and competence building. In: THE NELSON AND WINTER DRUID SUMMER CONFERENCE, 12-15 jun. 2001, Aalborg, Dinamarca. Anais... Aalborg, 2001

MIETTINEN, R. National innovation system - scientific concept of political rhetoric. Helsinque: Edita, 2002.

MYTELKA, L.; SMITH, K. Innovation theory and innovation policy: bridging the gap. In: THE NELSON AND WINTER DRUID SUMMER CONFERENCE, 12-15 jun. 2001, Aalborg, Dinamarca. Anais... Aalborg, 2001.

NELSON, R.; WINTER, S. An evolutionary theory of economic change. Cambridge, Mass.: Harvard University Press, 1982.

NONAKA, I.; TAKEUCHI, H. The knowledge-creating company. How Japanese companies create the dynamics of innovation. Oxford: Oxford University Press, 1995.

NORTH, D. Institutions. Journal of Economic Perspective, v. 5, n. 1, p. 97-112, 1991.

PEREZ, C. Technological revolutions and financial capital: the dynamics of bubbles and golden ages. Cheltemham: Edward Elgar, 2002.

The social and political challenge of the present paradigm shift. In: Norwegian Investorforum, 15-16 May, Oslo, Norway, 1997.

PEREZ, C.; SOETE, L. Catching up in technology. Entry barriers and windows of opportunity. In: DOSI, G. et al., (Ed.). Technical change and economic theory. London: Pinter, 1988.

PESSINI, J. A indústria brasileira de telecomunicações: uma tentativa de reinterpretação dos mercados recentes. Dissertação (Mestrado) - IE/Unicamp, Campinas, 1986. 
PIRAGIBE, C. Electronics industry in Brazil and the role of the State: some aspects. In: Brazil. Brasília: MCT/CNPq, 1988.

POLANYI, M. Personal knowledge towards a post-critical philosophy. London: Routledge, 1958.

PUTMAN, R. Making democracy work - civic traditions in modern Italy. Princenton, NJ: Princeton University Press, 1993.

ROSENBERG, N. Perspectives on technology. Cambridge: Cambridge University Press, 1976.

SCHIENSTOCK, G.; HÄAMÄLÄINEN, T. Transformation of the finnish innovation system. Helsinque: Sitra, 2001.

SCHMITZ, H.; CASSIOLATO, J. (Ed.). Hi-tech for industrial development - lessons from the Brazilian experience in electronics and automation. London: Routledge, 1992.

SZAPIRO, M. Downgrading local capabilities in IT: the telecom innovation system in Campinas. In: CASSIOLATO, J.; LASTRES, H.; MACIEL, M. (Ed.). Systems of innovation and development evidence from Brazil. Cheltenham: Edward Elgar, 2003.

SOUZA, C.; GARCIA, R. Sistemas locais de inovação no Estado de São Paulo. In: CASSIOLATO, J.; LASTRES, H. (Ed.). Globalização e Inovação Localizada - a experiência do Mercosul. Brasília: IBICT/MCT, 1999.

TIGRE, P.; FERRAZ, J. (Coord.). Avaliação e perspectivas tecnológicas das empresas estatais. Brasília: CNPq, 1989. Mimeografado.

TUOMI, I. From periphery to center: emerging research topics on knowledge society. Helsinque: Tekes, 2001.

VARGAS, M.; ALIEVI, R. Learning trajectories and upgrading strategies in the footwear productive system of Sinos Valley. In: CASSIOLATO, J.; LASTRES, H.; MACIEL, M. (Ed.). Systems of innovation and development - evidence from Brazil. Cheltenham: Edward Elgar, 2003
VILLASCHI, A. Paradigmas tecnológicos: uma visão histórica para a transição presente. Revista de Economia, v. 30, n. 1, p. 65-106, Curitiba: UFPR, 2004

The Brazilian national system of innovation opportunities and constraints for transforming technological dependency. Thesis $(\mathrm{PhD})$ - Birkbeck College, University of London, London, 1992.

VILLASCHI, A.; CAMPOS, R. Sistemas/arranjos produtivos localizados: conceitos históricos para novas abordagens. In: CASTILHOS, C. (Coord.). Programa de apoio aos sistemas locais de produção: a construção de uma política pública no RS. Porto Alegre: FEE, 2002.

VILLASCHI, A.; LIMA, E. The metal-mechanic production system in Espirito Santo: comodity exports and local industrial capabilities. In: CASSIOLATO, J.; LASTRES, H.; MACIEL, M. (Ed.). Systems of innovation and development - evidence from Brazil. Cheltenham: Edward Elgar, 2003.

Arlindo Villaschi: Diretor Executivo Suplente pelo Brasil e Suriname no Banco Interamericano de Desenvolvimento; Professor Associado de Economia, Universidade Federal do Espírito Santo; Pesquisador Associado da Rede de Pesquisa em Sistemas Produtivos e Inovadores Locais (arlindov@iadb.org; arlindo@villaschi.pro.br; arlindovillaschi@hotmail.com)

Artigo recebido em 27 de abril de 2005 . Aprovado em 31 de maio de 2005. 